\title{
A MAP OF THIS BOOK
}

If so much of deconstruction is concerned with the experience of aporia and impasse, then perhaps a map is not the most useful means by which to orientate oneself within the problems of deconstruction. However, the paralysis which comes with the conceptual difficulty of not knowing how to proceed does not necessarily preclude a knowledge of the terrain. For this reason then, a few 'manufacturer's instructions' on how to use this book. It is not another 'Derrida Reader'. It includes texts by Derrida, and deconstruction would not be what it now is without Derrida, but the book is not intended as an introduction or guide to the complex field of Derrida's writing. Rather, its purpose is to present the reader with as rich and diverse an introduction as possible to the entire work of deconstruction past and present. For all the reasons that will be given in this book, this goal is no doubt impossible. However, one day we will surely have to live without Derrida, just as surely as the work of deconstruction and the reading of Derrida's texts will continue in all their heterogeneity. While much deconstruction may seem like so many Talmudic glosses on Derrida's texts, this volume is motivated by the belief that for good or ill deconstruction has become a 'field of knowledge' in its own right. As such deconstruction - if it is to retain the name of deconstruction must lose the inhibitions which tie it to the unreconstructed desire for presence which places Jacques Derrida (man and texts) at the centre of an academic discipline. Derrida himself has explained the difficulties of escaping such essential desires, but the day must inevitably come when we no longer rely on fathers. It is a matter of the greatest importance that Derrida's texts should be set up to be worked and reworked by others. At no stage should Derrida's writing be allowed to occupy a privileged or 'transcendental' space within the discourse of deconstruction. If this is allowed to happen deconstruction will indeed become a 'school', with 'paternal' status accorded to certain texts, a 'presence' and authority bestowed upon Derrida as a person, its own set of legal injunctions and rules of behaviour, its own prefects whose readings are favoured over others, and its own pedagogical hierarchy. The highest compliment that one could pay to the work of Derrida might be to see his name disseminated across a range of texts, each one signed and countersigned by Derrida and his readers, each signature becoming more illegible and indistinguishable with every reinscription. In short, one cannot forget Derrida, but there is more to deconstruction than merely Derrida. 
This volume presents the reader (perhaps the singular reader of its title) with an introduction to a variety of work undertaken within the locus of deconstruction. It is not intended as a substitute for wide and rigorous reading within the ambit of deconstruction but, on the contrary, as a stimulus to the reader to explore beyond the confines of this selection and so to return to the text of Derrida itself. It goes without saying that this selection is partial, partisan, inadequate, and on the whole completely unjustifiable. However, as a rough rule of thumb, the eventualities which determined the cut of the decisions which included or excluded material were always pedagogical. The Reader assumes a student or novice audience, and is constructed with the demands of teaching in mind, but it is hoped that the range of its material (with new translations and previously unanthologised texts) will appeal to the researcher as a handy resource. The volume begins with a user-friendly introduction to some key ideas within deconstruction. It is followed by a prelude of sorts. The section 'Avant la Lettre' provides a selection of some of the important texts discussed by Derrida and deconstruction, texts which exemplify a deconstructive logic of their own without necessarily recognising themselves as such. This section could have been as long as the Reader itself: one could have easily added Condillac, Rousseau, Kant, Hegel, Flaubert, Nietzsche, Mallarme, Joyce, Celan, Ponge, Genet, Austin, etc. Perhaps this is the suggestion of a pedagogical text 'yet to come'.

With the progress of the Reader well established 'opening remarks' can begin. Derrida's essay 'A Number of Yes' has been described by Geoffrey Bennington as appearing 'to contain the whole of Derrida (if only you have read the rest) in a condensation that would demand hundreds of pages of commentary' (Bennington 1993: 202). This ought to make for an interesting seminar! The little text is metonymic of Derrida's place in this Reader: one must 'read the rest' and immerse oneself in the commentary for its own sake. Thereafter the Reader is divided into nine further sections, which represent the diversity of past and present work in/on deconstruction. Seven of these sections cover significant interests within deconstruction: Philosophy, Literature, Culture, Sexual Difference, Psychoanalysis, Politics and Ethics. The contents of individual sections attempt to stage a dialogue, which performs a particular line of argument. For example, in the 'Philosophy' section Rodolphe Gasché's essay responds to Richard Rorty's description of deconstruction as a theory of writing, while Geoffrey Bennington's review-essay offers a counterbalance to Gasché. The 'Literature' section gathers together a selection of texts on Hamlet as both a recognition of the diversity of opinion within deconstruction and as a pedagogical aid. Examples multiply within each section. Every text in these sections is accompanied by cross-references to other texts within the Reader. Because individual sections are ordered thematically, cross-references only refer to texts outside the section in which they appear. Given that there is potentially no limit to the interests of deconstruction, an accurate crossreferencing would involve listing all of the texts on every occasion. Indeed, in 
the manner of a Venn diagram, every section could be subsumed into every other section: the contamination of drugs being as relevant to the "law of genre [gender]' as the question of God to the problem of spectrality. Derrida's idea of the 'invaginated fold' might provide a more descriptive model here. However, given the pedagogical pressures at work in this text, each essay or extract is followed by a select, if inadequate, number of cross-references. The sensitive reader will no doubt identify more striking and unconventional routes of reading for themselves. The Reader ends with three attempts at closure. First, a collection of memorial pieces by Derrida for his 'philosophical friends'. Secondly, a series of 'closing statements', each one a previously unanthologised text. Finally, two bibliographies: one listing texts by Derrida and one listing texts by the other thinkers collected in this volume. Such a comprehensive display of anxiety for closure can only serve to open the Reader out onto the textual field it attempts to encapsulate and so encourage its user to be a reader of deconstruction.

The first problem which Deconstruction: A Reader encounters is the impossibility of its own name. 'Deconstruction' is of course only one term among many which Derrida uses in his early texts to describe his 'adventure' in philosophy. The word 'deconstruction' has, however, taken on a set of not always welcome meanings related to Derrida's philosophical practice and the interdisciplinary work associated with it. In various contexts 'deconstruction' has come to mean a method or theory of reading, a school of philosophical investigation, what Derrida 'does', what Derrida's 'followers' 'do', the totality of the institutional discourse surrounding Derrida's texts, any relativising or 'radical' aspect of 'postmodern' critical theory. Certainly, the majority of these uses of the term need to be challenged and none of them is satisfactory. The idea of a 'theory', that idea which calls itself theory, hides its own institutionalised assumptions in its own constant reinvention. In using the term theory one may be in danger of reinscribing or being recuperated by the very political gesture of mimesis (of the question of the copy or likeness and the ideal form) which the deconstruction attempts to undo. Deconstruction is not a delimitable entity, reducible to a collection of named scholars or to a set of procedural manoeuvres in textual analysis. Rather, deconstruction takes place in a singularity (it is 'always applied'). Deconstruction is what happens in the event of a reading, which attempts to open a text or institution to the movement of différance forgotten within it. There is no incorporeal syntax of deconstruction separate from its constant acts of reading. To confuse these events of reading with a 'theory' would be to burden deconstruction with the very logocentric confusion it seeks to dispel.

As a name, like any other proper name, the word 'deconstruction' is replaceable and in fact its replacement is made necessary by the impossibility of the 'proper' identified by deconstruction itself. However, because the term is replaceable it does not need to be replaced precisely because of its own 'improperity'. What could be more improper than, as this Reader does, to place 
essays by Levinas, Lyotard, Rorty, Benjamin, Norris, Belsey and de Man together under the same umbrella term? What connects these texts is not a 'method' or a 'school' but an openness to reading which responds to the possibilities of difference. If 'deconstruction' is an inappropriate name for the interdisciplinary discourse which relates itself to Derrida's texts, then it is an equally impertinent (and therefore apposite) name for a reader which offers a collection of readings impossibly related by difference. The 'deconstruction' in the title of this volume therefore does not attempt to designate a school of thinkers or a canon of exemplary methodologies, rather it suggests an interest in a movement of reading which responds to the invitation made by the endless work of Derrida's texts.

This volume must also negotiate what Peggy Kamuf calls 'the impossibility of position' suggested in the term 'Reader'. The reader is a genre of academic publishing, it is a selection of texts to be read. The reader is also the person who reads, and who works and reworks the texts which they read, imbricated within these texts and displaced by the reading process. If deconstruction is an experience of a question of reading then the very idea of the 'reader' may have to be examined by this volume as a precondition of the volume being allowed to say anything at all. It may be necessary to address the topic of reading as an opening onto the effects of the trace and as an accession to a context of writing. Deconstruction cannot be disentangled from the problems of reading. However, it may also be necessary to 'deconstruct' the very idea of the reader qua genre. If Deconstruction: A Reader is to mean anything at all (not just another commercial product, not just another 'theoretical' tool) it must rethink the institutional assumptions of the reader genre from the ground up. The point would be not to remove the volume from this genre but to give the genre the possibility of being thought. The possibility of thinking through a deconstruction reader might necessarily involve a putting into question of everything within a reader to which deconstruction might be subjugated, namely, the values of categorisation, selection, pedagogy, translation, and so forth. All of which can be deconstructed but which do not in themselves constitute a deconstruction. Ultimately, there may be something unquestioned, and therefore problematic, in the very idea of a deconstruction reader. Deconstruction: A Reader must question the problem of the programme and the resistance to programme or to 'family resemblances' implied by the genre of 'reader'. It must also accept that in order for the book to succeed as a deconstruction it must fail as a reader. 
